\title{
PENGEMBANGAN SKALA KETERAMPILAN SOSIAL MAHASISWA PGSD
}

\author{
Sri Budyartati *
}

\begin{abstract}
In Indonesia, social skills learning strategies into one of the specified component as a graduation requirement PPG (Professional Teacher Education). The policy as the aspect of the process that is weighted PPL large enough space that is 30 Placement assessment of social skills in the process of field practice, is the right decision, given the social skills can be seen clearly in the Program Particularly Student Conduct Study Elementary School Teacher and has implications reflecting broad holistic or overall competence, behavior is a person in general showed a tendency to someone in something.
\end{abstract}

Keyword:

\begin{abstract}
Abstrak
Di Indonesia strategi pembelajaran keterampilan sosial menjadi salah satu komponen yang ditetapkan sebagai syarat kelulusan PPG (Pendidikan Profesi Guru). Kebijakan tersebut sebagai aspek proses dalam PPL yang diberi bobot cukup besar yaitu 30. Penempatan ruang penilaian keterampilan sosial dalam proses praktek lapangan merupakan keputusan yang tepat, mengingat keterampilan sosial dapat terlihat jelas dalam perilaku mahasiswa khususnya Prodi Pendidikan Guru Sekolah Dasar dan memiliki implikasi yang luas yang mencerminkan kompetensi secara holistik atau menyeluruh, perilaku seseorang pada umumnya menunjukkan kecenderungan seseorang dalam sesuatu hal

Kata Kunci: Pengembangan Skala Keterampilan Sosial, Mahasiswa PGSD
\end{abstract}

\section{A. Pendahuluan}

Setiap desain pembelajaran terdapat dua aspek, yaitu: Instructional dan Nurturance. Selama ini dunia pendidikan di Indonesia lebih banyak mengedepankan instructional dan kurang memperhatikan nurturant, pembelajaran terpisah dari kehidupan nyata. Padahal pendidikan yang ideal seharusnya meliputi instructional dan nurturant yang bersifat nyata dan seimbang,sehingga pembelajaran menjadi lebih bermakna. Selama ini kehidupan sekolah dihabiskan untuk mengejar target berprestasi secara akademik. Padahal keberhasilan hidup dalam bermasyarakat tidak hanya berdasarkan akademik saja tetapi juga membutuhkan keterampilan sosial.

Lembaga pendidikan memiliki potensi yang besar dalam mengembangkan keterampilan sosial jika dalam kurikulum memiliki porsi yang seimbang dan sejalan antara instructional dan nurturant. Oleh karena itu keterampilan sosial kurang mendapatkan perhatian. Sejauh ini keterampilan sosial kurang diperhatikan dalam pembelajaran. Padahal bangsa yang berkarakter harus memiliki keterampilan

*Sri Budyartati adalah dosen Program Studi PGSD IKIP PGRI Madiun 
sosial yang memadai. Dengan kata lain keterampilan sosial adalah bagian penting dalam pendidikan karakter. Dalam konteks karakter ini (Lickona, 1997) untuk menjadi orang yang sopan, jujur, bertanggungjawab, adil, dan taat terhadap hukum dan aturan.

Mengajarkan keterampilan sosial merupakan tantangan para pendidik, bersosialisasi tidak boleh direduksi dengan pemaknaan sekedar bergaul dengan teman sebaya, tetapi harus melibatkan proses sadar untuk menguasai keterampilan sosial,pada berbagai kompetensi sebagai contoh, misalnya pembelajaran pada bahasa selain mengajarkan kompetensi bahasa (mendengar,baca,tulis,dan berbicara)sekaligus merupakan wahana penanaman nilai kehidupan, budi pekerti dan menumbuh-kembangkan keterampilan sosial yang diperlukan anak-anak agar mereka terampil saat terlibat di masyarakat di masa dewasanya nanti. Dapat dikatakan bahwa salah satu cara untuk memadukan antara tata nilai (sebagai bagian yang penting dalam memahami keterampilan sosial) dan kemampuan berbahasa adalah mengekspos pilihan kata dan bahasa yang positif sejak dini.

Oleh karena itu, Dosen dapat melakukan penilaian keterampilan sosial para mahasiswa dengan observasi terhadap Mahasiswa yang dibinanya, . Hasil observasi, dapat dijadikan sebagai umpan balik dalam pembinaan. Observasi perilaku dapat dilakukan dengan menggunakan buku cacatan khusus tentang kejadian-kejadian berkaitan dengan siswa selama di sekolah atau dengan menilai skala keterampilan sosial yang diisi oleh para mahasiswa

Tujuan penelitian ini adalah: 1. Mengembangkan perangkat tes keterampilan sosial berdasarkan konsep keterampilan sosial yang telah teridentifikasi pada observasi awal, 2.Melakukan validasi perangkat tes keterampilan sosial yang telah dikembangkan, sehingga menghasilkan istrumen pengukuran keterampilan sosial yang berbentuk skala. 3. Diseminasi hasil penelitian melalui pertemuan ilmiah baik itu seminar hasil maupun seminar himpunan ahli evaluasi

Penelitian pendahuluan meliputi studi pustaka mengenai aspek-aspek keterampilan sosial secara teoritis, dan observasi lapangan untuk aspek-aspek praktis dari keterampilan sosial. Selanjutnya aspek-aspek praktis dan teoritis dari keterampilan sosial tersebut dijadikan sebagai indikator keterampilan sosial yang akan dikembangkan oleh peneliti. Indikator-indikator itu selanjutnya dijabarkan dalam item-item. Setelah diperoleh instrumen yang terkalibrasi dilakukan analisis faktor konfirmatori (CFA), untuk mengkonfirmasikan aspek-aspek yang diukur sudah sesuai dengan konstruknya, sehingga diperoleh validitas konstruk. Prosedur pengembangan skala yang diperlukan dalam proses pengembangan skala keterampilan sosial digunakan agar skala yang dihasilkan memenuhi standar psikometri yang baku. (Netemyer, Djemari 2008, Setiadi 2008, Purwanto 2007, Azwar 2012, Lorin 1981) Menurut Djemari (2008.hlm. 108-109), Ada sepuluh langkah yang harus diikuti dalam mengembangkan instrument afektif, yaitu: 1.Menentukan spesifikasi instrumen, 2.Menulis instrumen, 3.Menentukan skala instrumen, 4.Menentukan sistem penskoran, 5.Menelaah instrumen, 6.Melakukan ujicoba, 7.Menganalisis instrumen, 8. Merakit instrumen, 9. Melaksanakan pengukuran, 10.Menafsirkan hasil pengukuran. Bagan di bawah ini menjelaskan model pengembangan skala keterampilan sosial yang akan digunakan dalam penelitian ini. 


\section{B. Metode}

Penelitian pendahuluan meliputi studi pustaka mengenai aspek-aspek keterampilan sosial secara teoritis, dan observasi lapangan untuk aspek-aspek praktis dari keterampilan sosial pada anak usia dini. Selanjutnya aspek-aspek praktis dan teoritis dari keterampilan sosial tersebut dijadikan sebagai indikator keterampilan sosial yang akan dikembangkan oleh peneliti. Indikator-indikator itu selanjutnya dijabarkan dalam item-item.

Setelah diperoleh instrumen yang terkalibrasi dilakukan analisis faktor konfirmatori (CFA), untuk mengkonfirmasikan aspek-aspek yang diukur sudah sesuai dengan konstruknya, sehingga diperoleh validitas konstruk. Prosedur pengembangan skala yang diperlukan dalam proses pengembangan skala keterampilan sosial digunakan agar skala yang dihasilkan memenuhi standar psikometri yang baku. (Netemyer, Djemari 2008, Setiadi 2008, Purwanto 2007, Azwar 2012, Lorin 1981)

Menurut Djemari (2008, 108-109), Ada sepuluh langkah yang harus diikuti dalam mengembangkan instrument afektif, yaitu: 1.Menentukan spesifikasi instrumen, 2.Menulis instrumen, 3.Menentukan skala instrumen, 4.Menentukan sistem penskoran, 5.Menelaah instrumen, 6.Melakukan ujicoba, 7.Menganalisis instrumen, 8. Merakit instrumen, 9. Melaksanakan pengukuran, 10.Menafsirkan hasil pengukuran. Bagan di bawah ini menjelaskan model pengembangan skala keterampilan sosial yang akan digunakan dalam penelitian ini

\section{Menentukan spesifikasi instrumen}

Spesifikasi instrumen terdiri dari tujuan dan kisi-kisi instrumen. Dalam menyusun spesifikasi instrumen, ada empat hal yang harus diperhatikan yaitu: 1.Menentukan tujuan pengukuran, 2.Menyusun kisi-kisi instrumen, 3.Memilih bentuk dan format instrumen, 4.Menentukan panjang instrumen (Djemari 2008). Sedangkan menurut (Purwanto,2007:105-122) Spesifikasi yang dikembangkan menyangkut penentuan jenis instrumen, banyak butir, waktu uji coba, peserta uji coba, aturan skoring, dst. Kisi-kisi instrumen adalah rancangan sebagai dasar penulisan item

\section{Penulisan Item}

Senada dengan pendapat Djemari dan Purwanto di atas, Azwar Saifudin (2012, 14-17), menyatakan bahwa awal kerja penyusunan suatu skala psikologi dimulai dari melakukan identifikasi tujuan ukur, yaitu memilih suatu definisi, mengenali dan memahami dengan seksama teori yang mendasari konstruk psikologi atribut yang hendak diukur.

Dimensi perilaku keterampilan sosial, dioperasionalkan dalam tiga sub dimensi yang terdiri dalam dimensi kecerdasan emosional, kecerdasan sosial, dan kecerdasan budaya. Operasionalisasi ini dirumuskan ke dalam bentuk indikator perilaku. Himpunan indikator-indikator perilaku beserta dimensi yang diwakilinya kemudian dituangkan dalam kisi-kisi atau blue print, yang setelah dilengkapi dengan spesifikasi skala, akan dijadikan acuan bagi para penulis item.

Pada perancangan skala psikologi penentuan format itemnya tidak terlalu mempertimbangkan keadaan subjek maupun tujuan penggunaan skala. Biasanya pemilihan format skala lebih tergantung pada keunggulan teoretik dan sisi praktis penggunaan format yang bersangkutan. 


\section{Telaah item}

Telaah pertama harus dilakukan oleh penulis item sendiri, yaitu dengan selalu memeriksa ulang setiap aitem yang baru saja ditulis apakah telah sesuai dengan indikator perilaku yang hendak diungkap dan apakah juga tidak keluar dari pedoman penulisan item. Apabila semua aitem telah selesai ditulis, reviu dilakukan oleh beberapa orang yang berkompeten (sebagai panel).

\section{Ujicoba}

Uji coba terbatas dilakukan guna mendapatkan data dari responden yang akan dikalibrasi sehingga diperoleh data distribusi parameter butir dan parameter kemampuan. Hasil kalibrasi tersebut yang akan dianalisis dengan analisis faktor konfirmatori (CFA) untuk mendapatkan instrumen yang konstruksinya memenuhi validitas konstruk

a. Subjek Uji Coba

Subjek uji coba pada penelitian ini adalah mahasiswa PGSD IKIP PGRI Madiun

b. Jenis Data

Model teori respons item politomus diperlukan untuk menggambarkan hubungan yang tidak linear antara skala keterampilan sosial dan probabilitas menjawab respon item pada kategori tertentu.

Banyak model yang menggunakan penskoran politomus, di antaranya adalah the graded response model (GRM), the modified graded response model (M-GRM), the partial credit model (PCM), the generalized partial credit model $(G-P C M)$, rating scale model (RSM) dan the nominal response model (NRM)

(Embretson \& Reise, 2000:96-121). Semua model tersebut mendasarkan pada asumsi bahwa respons (jawaban) peserta tes pada suatu item tes bergantung pada kemampuan peserta tes yang diukur menggunakan skala unidimensi.

Salah satu model yang sesuai dengan pengujian keterampilan sosial yang struktur penskorannya berkaitan dengan pilihan sebelumnya adalah graded response model Samejima (1969). Di bawah ini diuraikan tentang model respons berjenjang (GRM) Samejma.

\section{Analisis instrument dengan Graded Response Model (GRM)}

Salah satu model IRT politomus yang dapat digunakan untuk mengukur skala Likert adalah graded response model (GRM) dikembangkan oleh Samejima (1969). Model ini digunakan untuk data berjenjang dan digunakan ketika respon peserta terhadap item merupakan skor kategori yang berurutan dan cenderung meningkat. Dalam tipe Likert respon diskor 0,1,2,3,4 yang merupakan skor berjenjang dan yang paling kecil hingga besar secara berurutan.

\section{Merakit Instrumen}

Dimulai dengan membuang butir yang buruk dan mengambil butir butir yang baik. Selanjutnya guna mendapatkan validitas konstruk maka butir-butir baik yang diambil tersebut dikonfirmasikan dengan metode Confirmatory Faktor Analisis (CFA).

\section{Melakukan Pengukuran}

Pengukuran ini akan menggunakan bantuan program lisrel. Analisis faktor konfirmatori adalah metode analisis multivariat yang digunakan untuk menguji atau mengkonfirmasikan model yang dihipotesiskan. Sesuai dengan tujuannya, CFA dimaksudkan : (1) untuk menguji hypothesis tentang satu atau lebih faktor (konstruk psikologi dalam ketrampilan sosial) serta saling keterkaitan antar faktor 
tersebut sesuai model teori yang ditetapkan, dan (2) untuk menguji validitas dari setiap indikator yang digunakan untuk mengukur faktor/ konstruk tersebut yaitu: items, atau sub-test.

\section{Hasil}

Pada tahap awal penyusunan instrumen disertasi tersebut pada hari Selasa tanggal 24 Juni 2014, telah mengadakan Focus Group Discussion (FGD) bersama 5 orang dosen (DOSEN PGSD IKIP PGRI MADIUN), 1 ahli bahasa, 1 orang ahli evaluasi, dan 1 psikolog perkembangan) untuk merumuskan aspek-aspek, kisikisi, dan pedoman penyekoran pada instrumen keterampilan sosial pada mahasiswa PGSD.

Untuk efektifitas dan efesiensi pada saat FGD tidak hanya melakukan diskusi merumuskan aspek-aspek, kisi-kisi, dan pedoman penyekoran pada instrument namun pada saat setelah perumusan tersebut disepakati maka dilanjutkan dengan penelahaan instrument untuk menemukan validitas isi

\section{Pembahasan}

Setelah uji validitas isi maka selanjutnya adalah Uji Reliabilitas dilakukan dengan uji Alpha Cronbach. Rumus Alpha Cronbach sebagai berikut:

$$
\alpha=\left(\frac{K}{K-1}\right)\left(\frac{s_{r}^{2}-\Sigma s_{i}^{2}}{s_{x}^{2}}\right)
$$

Note:

$$
\begin{array}{ll}
\alpha & =\text { Koefisien reliabilitas Alpha Cronbach } \\
K & =\text { Jumlah item pertany aan yang diuji } \\
\Sigma s_{i}^{2} & =\text { Jumlah varians skor item } \\
S X^{2} & =\text { Varians skor-skor tes (seluruh item K) }
\end{array}
$$

Jika nilai alpha $>0,7$ artinya reliabilitas mencukupi (sufficient reliability) sementara jika alpha $>0,80$ ini mensugestikan seluruh item reliabel dan seluruh tes secara konsisten secara internal karena memiliki reliabilitas yang kuat.[3] Atau, ada pula yang memaknakannya sebagai berikut:

1. Jika alpha $>0,90$ maka reliabilitas sempurna

2. Jika alpha antara $0,70-0,90$ maka reliabilitas tinggi

3. Jika alpha antara 0,50-0,70 maka reliabilitas moderat

4. Jika alpha $<0,50$ maka reliabilitas rendah

Jika alpha rendah, kemungkinan satu atau beberapa item tidak reliabel: Segera identifikasi dengan prosedur analisis per item. Item Analysis adalah kelanjutan dari tes Aplha sebelumnya guna melihat item-item tertentu yang tidak reliabel. Lewat ItemAnalysis ini maka satu atau beberapa item yang tidak reliabel dapat dibuang sehingga Alpha dapat lebih tinggi lagi nilainya.

Reliabilitas item diuji dengan melihat Koefisien Alpha dengan melakukan Reliability Analysis dengan SPSS ver. 16.0 for Windows. Akan dilihat nilai Alpha-Cronbach untuk reliabilitas keseluruhan item dalam satu variabel. Agar lebih teliti, dengan menggunakan SPSS, juga akan dilihat kolom Corrected Item Total Correlation. 
Nilai tiap-tiap item sebaiknya $\geq 0.40$ sehingga membuktikan bahwa item tersebut dapat dikatakan punya reliabilitas Konsistensi Internal.[5] Item-item yang punya koefisien korelasi $<0.40$ akan dibuang kemudian Uji Reliabilitas item diulang dengan tidak menyertakan item yang tidak reliabel tersebut. Demikian terus dilakukan hingga Koefisien Reliabilitas masing-masing item adalah $\geq 0.40$.

Cara Uji Reliabilitas dengan SPSS:

1. Klik Analyze $>$ Scale $>$ Reliability Analysis

2. Masukkan seluruh item Variabel X ke Items

3. Pastikan pada Model terpilih Alpha

4. Klik OK

Kalibrasi butir soal dan pengukuran kemampuan orang merupakan proses estimasi parameter pada model respon butir. Model persamaan dasar Rasch adalah model probabilistik yang mencakup hasil dari suatu interaksi butir soal-orang. Proses mengestimasi kemampuan orang dinamakan pengukuran, sedangkan proses mengestimasi parameter tingkat kesukaran butir soal dinamakan kalibrasi. Jadi kalibrasi soal merupakan proses penyamaan skala soal yang didasarkan pada tingkat kesukaran butir soal dan tingkat kemampuan siswa. Adapun ciri suatu skala adalah mempunyai titik awal, biasanya 0 , dan mempunyai satuan ukuran atau unit pengukuran.

Prosedur estimasi dapat dilakukan dengan tangan atau komputer. Ada beberapa langkah yang dapat dilakukan dalam mengkalibrasi butir dan menguki.r kemampuan orang dengan tangan (Wright and Linacre, 1992: 32-45) seperti berikut.

a. Menyusun jawaban peserta didik untuk setiap butir soal ke dalam tabel.

Dalam menyusun jawaban peserta didik untuk setiap butir ke dalam tabel perlu disediakan kolom: (1) siswa, (2) butir soal, (3) skor siswa, dan (4) skor butir soal. Data berbentuk angka 1 untuk jawaban benar dan 0 untuk jawaban salah.

b. Mengedit data

Berdasarkan model Rasch, butir soal yang dijawab siswa betul semua atau salah semua dan siswa yang dapat menjawab dengan betul semua atau salah semua, soal atau siswa yang bersangkutan tidak dianalisis atau dikeluarkan dari tabel. Pada langkah kedua ini perlu disediakan tambahan kolom: (1) proporsi skor siswa dan (2) proporsi skor butir soal. Proporsi skor peserta didik adalah skor siswa : jumlah butir soal; sedangkan proporsi skor soal adalah skor soal : jumlah siswa.

c. Menghitung distribusi skor soal

Berdasarkan skor soal yang sudah diedit, maka skor soal diklasifikasikan menjadi beberapa kelompok berdasarkan skor yang sama. Untuk memudahkan penghitungan Distribusi skor butir soal, maka perlu disusun beberapa kolom di dalam tabel, seperti kolom: (1) kelompok skor soal (i) yaitu kelompok skor yang didasarkan pada skor soal yang sama, kolom ini berhubungan langsung dengan kolom 2 dan kolom 3; (2) nomor butir soal, (3) skor soal ( $\mathrm{Si}$ ), (4) frekuensi soal (Fi) yaitu jumlah soal yang memiliki skorsoal sama; (5) proporsi benar (Pi) yaitu $\mathrm{Si}$ : jumlah peserta tes; (6) proporsi salah (1-Pi), (7) logit (log odds unit)-proporsi salah (Xi) yaitu Ln [(1 -Pi)/Pi], (8) hasil kali frekuensi soal dengan logit proporsi salah (FiXi), (9) kuadrat logit proporsi salah (FiXi) ${ }^{2}$, (10) hasil kali frekuensi soal dengan kuadrat logit proporsi salah( $\left.\mathrm{FiXi}^{2}\right),(11)$ inisial kalibrasi butir soal yaitu di $=\mathrm{Xi}$ - nilal rata-rata skor soal, dan (12) hasil kali antara frekuensi soal dengan kuadrat nilai rata-rata skor coal (FIX ?). 
d. Menghitung distribusi skor peserta didik.

Untuk memudahkan di dalam menghitung distribusi skor peserta didik perlu disusun beberapa kolom yaitu kolom: (1) kemungkinan skor peserta didik (r) yang disusun secara berurutan dimulai dan skor terendah sampai tertinggi; (2) skor peserta didik, yaitu berupa toli skor peserta didik; (3) frekuensi peserta didik (nr) yang memperoleh skor; (4) proporsi benar ( $\left.\mathrm{Pi}^{-}\right)$yaitu skor peserta didik dibagi jumlah soal, (5) logit proporsi benar (Yr) yaitu Ln [Pr/(1-Pr)]; (6) perkalian antara frekuensi siswa dengan logit proporsi benar (nrYr); (7) logic proporsi benar yang dikuadraktan (Yr kuadrat); (8) hasil perkalian antara frekuensi peserta didik dengan logic proporsi benar yang dikuadratkan (nrYr kuadrat); (9) inisial pengukuran kemampuan peserta didik (br Yr); (10) perkalian antara frekuensi peserta didik dengan nilai rata-rata skor peserta didik (nrYr kuadrat).

e. Menghitung faktor ekspansi kemampuan peserta didik (x) dan kesukaran butir soal (Y). Dalam menghitung faktor ekspansi diperlukan variasi distribusi kelompok skor soal (U) dan variance distribusi kelompok skor siswa (V). Faktor ekspansi kemampuan peserta didik terhadap keluasan tes adalah $\mathrm{X}=$ [ (I 4-U/2,89)/ (1-UV/8,35)]" ${ }^{2}$ Faktor ekspansi kemampuan peserta didik terhadap penyebaran sampel adalah $\mathrm{X}=\_[(1+\mathrm{U} / 2,89) /(1-\mathrm{UV} / 8,35)]^{12}$

f. Menghitung tingkat kesukaran dan kesalahan standar butir soal

Dalam menghitung tingkat kesukaran dan kesalahan standar soal perlu disusun beberapa kolom di dalam tabel, yaitu kolom: (1) kelompok skor soal (1); (2) nomor soal; (3) inisial kalibrasi soal (d); (4) faktor ekspansi kesukaran soal terhadap penyebaran sampel (Y); (5) tingkat kesukaran soal atau Yd; = d;; (6) skor soal (S); (7) kesalahan standar kalibrasi soal yang dikoreksi [SE(di)] atau $\mathrm{SE}=[\mathrm{N} / \mathrm{Si}(\mathrm{N}-\mathrm{Si})]^{112}$

g. Menghitung tingkat kemampuan dan kesalahan standar siswa

Dalam menghitung tingkat kemampuan dan kesalahan standar siswa disusun beberapa kolom, yaitu kolom: (1) kemungkinan skor siswa (r); (2) initial pengukuran kemampuan siswa (br); (3) faktor ekspansi kemampuan siswa terhadap keluasan tes (X); (4) tingkat kemampuan siswa (br) atau (Xbr); (5) kesalahan standar pengukuran kemampuan siswa yang dikoreksi [SE (br)] yaitu X [ L/r (L-r)] ${ }^{112}$; (6) peserta tes. 


\section{DAFTAR RUJUKAN}

Andersen, Lorin. W. (1981). Assessing Affective Characteristic In The Schools.Boston: Allyn and Bacon.

Curtis, A. (1998). A curriculum for the pre-school child. New York: Routledge.

Depdiknas, Kerjasama Antara Kemdiknas Dirjrn Dikti Diktendik,(2007), Konsep Dasar Pendidikan Kecakapan Hidup, Buku 2 seri Pendidikan Kecakapan Hidup Unesco Jakarta Office.

Djohan, Jurnal Penelitian dan Evaluasi Pendidikan Vol. 13, No. 1, Thn. 2009 (12).

Goleman,Daniel 2007 Social Intelligence New Science Of Human Relationships, Bantam Dell,NY,USA (11).

Linn, R. L. (1989). Educational measurement. $3^{\text {rd }}$ Edition. New York, NY: Macmillan Publishing Company.

Lawhon, T., Lawhon, D. C. (2000).Promoting social skill in young children. Early Childhood Education Journal, Vol. 28, No. 2.

Mardapi Djemari (2008) Teknik Penyusunan Instrumen Tes Dan Nontes Mitra, Jogjakarta Mitra Cendikia Offset.

Purwanto.2006.Instrumen Penelitian Sosial dan Pendidikan. Yogyakarta : Pustaka PelajarPeterson, Brooks, 2004 Cultural Intelligence : A Guide To Working With People From Other Cultures(18).

Ramdhani, N. (1991). Standarisasi skala tingkah laku sosial. Laporan Penelitian. Yogyakarta : Fakultas Psikologi UGM.

Rick Lavoie (2005) Social Skill Autopsies: A Strategy to Promote and Develop Social Competencies. http://www.ldonline.org/article/Social_Skill_ Autopsies\%3A_A_Strategy_to_Promote_and_Develop_Social_Competencs

Roid, Gale H and Thomas M. Haladyna. (1982). A Thechnology for Test-Item Writing. London: Academic Press, Inc. 